\title{
Otolith-based assessment of recruitment variation in a North Pacific seamount population of armorhead Pseudopentaceros wheeleri
}

\author{
Robert L. Humphreys Jr* \\ Honolulu Laboratory, Southwest Fisheries Science Center, National Marine Fisheries Service, NOAA, 2570 Dole Street, \\ Honolulu, Hawaii 96822-2396, USA
}

\begin{abstract}
An investigation into armorhead Pseudopentaceros wheeleri recruitment variation at Southeast Hancock Seamount (in the central North Pacific) focused on the examination of recruit characteristics, primarily those derived from otolith-increment analysis. Otoliths from recruits were sampled from years representing relatively strong (509 metric tons [t] in 1980), moderate (58 t in 1986), and weak (1 t in 1989) recruitment biomass. Recruit body length was also examined among these 3 years and from 10 additional years, providing even higher recruitment contrast. Transverse sections of sagittal otoliths were prepared, and yielded information on the mean and variability in pre-recruit pelagic duration and increment-width profiles. Mean length of female recruits, and to a lesser extent of mean pelagic duration, decreased with increasing recruitment strength. Although generally similar in shape, the mean increment-width sequence spanning the first $1.8 \mathrm{yr}$ of the $2+\mathrm{yr}$ pelagic phase differed among recruit years. Transitions in sequential increment-width (inflection points) were exhibited among all recruit years and occurred primarily within the first pelagic year interval. The weak 1989 recruit year was most distinct among recruit years in exhibiting lower increment widths at each of these inflection points.
\end{abstract}

KEY WORDS: Recruitment variation - Characteristics of recruits · Pelagic duration · Recruit size . Otolith-increment width · Armorhead $\cdot$ Pseudopentaceros wheeleri $\cdot$ Seamounts

\section{INTRODUCTION}

Armorhead Pseudopentaceros wheeleri have been the target of an international bottom-trawl fishery since late 1967, when large demersal aggregations were found associated with the summits and upper slopes of the southern Emperor-northern Hawaiian Ridge (SE-NHR) seamounts in the temperate central North Pacific (Uchida \& Tagami 1984, Sasaki 1986). The seamounts are remote, widespread, and experience temperate oceanographic conditions distinct from the subtropical regime of the adjacent Hawaiian Archipelago. Armorhead undergo a lengthy epipelagic prerecruit phase in subarctic North Pacific waters distant from the SE-NHR seamounts. At the time of annual

*E-mail: robert.humphreys@noaa.gov spring - early summer recruitment (settlement and recruitment into the fishery are synonymous), recruiting individuals have attained maximum size (primarily 28 to $33 \mathrm{~cm}$ fork length, FL) but remain nonreproductive (Humphreys et al. 1989). Post-recruit movement of armorhead between seamounts is considered unlikely. Armorhead cease somatic growth after recruitment, mature, spawning annually during November to March (Japan Fisheries Agency 1974, Sasaki 1974, Bilim et al. 1978), and may survive 4 to $5 \mathrm{yr}$ at the seamounts. During seamount residence, individuals gradually become emaciated and experience an irreversible decline in somatic weight (Humphreys et al. 1989, Somerton \& Kikkawa 1992). Annual increases in armorhead biomass at these seamounts is therefore solely dependent on recruitment. The Japanese SENHR armorhead fishery experienced an initial period of high annual catches (20000 to 30000 t) during 1969 
to 1975 (Takahashi \& Sasaki 1977) and then plummeted in 1976 through 1991 to <3500 t annually (Sasaki 1986 unpubl. data, National Research Institute of Far Seas Fisheries, Shimizu, Japan). A concurrent Soviet fishery may have taken twice this amount, but showed a similar pattern of decline (Borets 1976).

Previous studies of armorhead recruitment-fluctuation (Wetherall \& Yong 1986, Somerton \& Kikkawa 1992) have not found a clear stock-recruitment relationship. Boehlert \& Sasaki (1988) suggest that stochastic environmental processes (independent of spawning stock) may exert a major influence on subsequent armorhead recruitment. Recruitment hypotheses which invoke such processes have primarily been investigated using statistical searches for environmental correlates (Rothschild 1986), process-oriented field studies typically limited (by inherent sampling constraints) to the larval stage (Frank \& Leggett 1994), or integrative studies based on both approaches (Tyler 1992).

Another approach toward investigating recruitment advocated by Fritz et al. (1990) and Taggart \& Frank (1990) is to focus instead on the 'characteristics of survivors'. Several studies have stressed the importance of expanding field studies to pre-recruit stages beyond the larval phase (Bakun et al. 1982, Anderson 1988, Peterman et al. 1988). If mortality acts nonrandomly, particularly during juvenile life-history stages, survivors may possess particular phenotypic characteristics which enhance survival (Miller 1997, Sogard 1997). Unfortunately, sampling of pre-recruit armor-

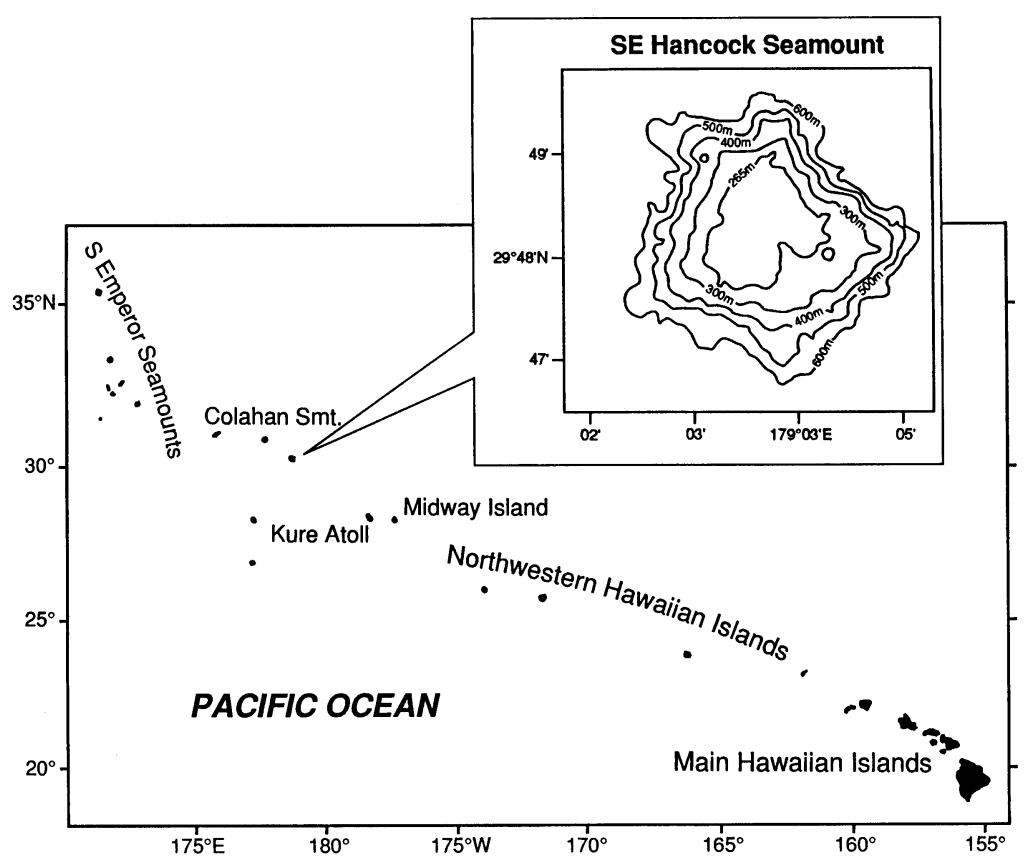

Fig. 1. Pseudopentaceros wheeleri. Location of armorhead recruit sampling site at Southeast (SE) Hancock Seamount head remains impractical due to the expense, isolation, expansive pelagic habitat, and wide size range (1 to $30 \mathrm{~cm} \mathrm{FL}$ ) that characterizes this prolonged pre-recruit pelagic stage. An alternate tactic is employed that still relies on the characteristics of survivors rather than the average fish, but examines only those individuals that survive the entire recruitment process (as employed by Frank 1991). In this study, internal increments within the sagittal otoliths of armorhead recruits are examined to determine pelagic duration and the sequential increment-width profile outward from the core. The body length of recruit individuals, together with these 2 otolith-derived characters, are used to compare recruit year classes taken from a single oceanic seamount that differed by $>3$ orders of magnitude in recruitment biomass. The objective of this study was to examine any possible relationship between these 'characteristics of recruits' and recruitment strength that might provide a means of qualitatively pro-rating future recruitment strength.

\section{MATERIALS AND METHODS}

Armorhead samples. Whole recruit specimens of Pseudopentaceros wheeleri were collected from the summit (265 to $300 \mathrm{~m}$ depth) of Southeast (SE) Hancock Seamount, located at $29^{\circ} 48^{\prime} \mathrm{N}, 179^{\circ} 04^{\prime} \mathrm{E}$, in the southern portion of the SE-NHR (Fig. 1). Specimens were obtained from years representing relatively high (509.2 $\mathrm{t}$ in 1980), moderate (58.3 $\mathrm{t}$ in 1986), and low $(1.2 \mathrm{t}$ in 1989) recruitment-biomass strength, as determined from researchstock assessment cruises and foreign observer data for SE Hancock Seamount (Somerton \& Kikkawa 1992).

Random samples of 112 and 208 recruits (both sexes present) were collected from trawl catches during August to October 1981 (for 1980 recruits) and August 1986, respectively. Recruits from 1980 were distinguishable from the few 1981 recruits at the time of collection by their leaner body depth and greater sagittal otolith width. The 1989 recruits were sampled with bottom longline gear in July 1989; their scarcity necessitated that all 135 recruits captured be retained as specimens. Comparison of fork length and body depth distribution among recruits from one of the recruit year-classes (1986) collected by both gear types during August 1986 indicated no significant gear selectivity. Although some recruitment occurs throughout the summer, 
highest recruitment occurs by July (Humphreys et al. 1993), thus minimizing the effects of bias in the 1986 and 1989 samples caused by substantial post-collection recruitment. Although the 1980 recruit population was exposed to potentially greater mortality prior to sampling in 1981, it is assumed that population characteristics of the original 1980 recruits were not altered via selective post-recruitment mortality.

An additional 40 specimens of newly arrived recruits were randomly collected from trawl hauls at SE Hancock in June 1983. Sagittae from these new recruits were examined to check the presence and placement of 'settlement marks'. Sixty armorhead collected from Koko Seamount (600 km northwest of SE Hancock) in August 1988 were used to check for similarity in increment-width profiles among recruits at a larger and distant seamount.

Pre-recruit pelagic specimens $(n=309)$ were collected from Japanese squid drift gill-net operations in the central subarctic North Pacific over 6 yr (1984 and 1985, 1989 to 1992). This collection included one large ( $\mathrm{n}=150)$ sample of pre-recruits from a single yearclass captured by the RV 'Shoyo Maru' during a drift gill-net operation at $41^{\circ} 28^{\prime} \mathrm{N}, 157^{\circ} 30^{\prime} \mathrm{W}$ on 16 July 1990.

Otolith preparation. Sagittal otoliths were used exclusively. The opacity, curvature, and thickness of sagittae required sectioning to view internal increments. Transverse sections contained the central core and bisected the associated mid-dorsal growth prism. Sagittae were cast in clear polyester resin and transversely sectioned on a low-speed saw. The resulting sections were ground on No. 600 wet/dry sandpaper, polished with alumina $(0.05 \mu \mathrm{m}$ particle size) and etched in porcine pancreatin. Transverse sections viewed under scanning electron microscopy (SEM) were attached to aluminum stubs and sputter-coated with gold prior to examination.

Microscope and measurement procedures. Light microscopy of transverse sections was performed at $1500 \times$ magnification under oil immersion. Five-increment width measures were conducted sequentially, starting from the core outward along the path of maximum growth, using a calibrated ocular micrometer with a minimum scale division of $1 \mu \mathrm{m}$. This procedure was conducted on each transverse section 3 times and then averaged. SEM photos of the outer edge of sagittal sections from 3 adult-size pelagic individuals were obtained at 300 to $2000 \times$ magnification to compare with light microscopy results.

Statistical procedures. The hypothesis of daily increment formation in sagittae of pelagic-staged armorhead was put to a rough test by first determining total increment counts and then backcalculating individual birthdates. These backcalculated birthdates were compared to a binomial distribution of random birthdates where the expected probabilities within and outside the November to March spawning season would be $p=0.414(151 / 365 d)$ and $q=0.586(214 / 365 d)$, respectively. This analysis, however, does not serve as a true test for validation; therefore, the assumption of daily increment deposition remains. The coincidence of settlement-mark formation in sagittal otoliths to time of seamount recruitment was tested using a $\chi^{2}$-analysis comparison of new recruits and adult-size pelagic individuals (the latter used as controls). Recruit-year comparisons of pelagic duration employed a balanced $(n=$ 32 for each recruit-year) 1-way ANOVA with orthogonal contrasts.

The relative variation of biological characters were evaluated via coefficient of variation $\left(\mathrm{CV}_{i} \mathrm{CV}=\right.$ $\mathrm{SD} / \mathrm{mean}$ ). Because of the small sample sizes used for pelagic-duration determinations in each of the 3 recruit years $(\mathrm{n}=32)$, a modified coefficient of variation $\left(\mathrm{CV}^{\prime}\right)$ was calculated using the bias-correcting formula $\left(C^{\prime}=(1+1 /[4 n]) \times C V\right)$ of Haldane (1955). Since linear growth ceases after recruitment, the $\mathrm{CV}^{\prime}$ in recruit FL from each of the 3 pelagic-duration recruit year samples was also evaluated. Tests for recruit-year differences in the $\mathrm{CV}^{\prime}$ of pelagic duration versus body length used the modified Student's $t$-test statistic shown in Eqs. (11) \& (12) of Sokal \& Braumann (1980). Larger samples derived from length-frequency data compiled at sea were used to regress mean female body length from each of the 3 recruit years plus an additional $10 \mathrm{yr}(1973,1978,1981,1984,1985,1987$, 1988, 1990, 1992, 1993) against recruitment-biomass (corresponding annual recruitment-biomass estimates derived from Somerton \& Kikkawa 1992). The 1973 recruitment-biomass was estimated as the product of the population biomass in 1973 (taken from Somerton \& Kikkawa 1992) and the peak proportion of new recruits determined from length-weight data (Boehlert \& Sasaki 1988). Recruits were identified in the datasets as those individuals with a fatness index (body depth at first anal spine (BDEPTH)/FL) $\geq 0.26$ (Humphreys et al. 1993). Prior to 1985, measurements of FL and weight (WT), but not BDEPTH, were routinely collected. To estimate BDEPTH from other measures, the Somerton \& Kikkawa multiple regression for females was used:

$$
\begin{aligned}
\mathrm{BDEPTH}(\mathrm{mm}) & =86.69-0.19 \mathrm{FL}(\mathrm{mm})+0.10 \mathrm{WT}(\mathrm{g}) \\
& {\left[\mathrm{n}=436, \mathrm{r}^{2}=0.91\right] }
\end{aligned}
$$

Analysis of individual 5-increment width-sequences was conducted using multivariate analysis of variance with repeated measures (MANOVAR). The 5-increment width-sequences were $\log _{10}(x+1)$ transformed (preferred over $\log _{10} X$ as explained in Zar 1984) to better ensure that variances were independent of their means. The independent variables included age, 
recruit-year, otolith section-angle, and interaction effects of the latter 2 variables. Analysis was restricted to the first 660 increment intervals (Age $1.8 \mathrm{yr}$ ) of the pelagic stage, since subsequent individual incrementwidths were nearly constant and at the limits of measurement $(\sim 1 \mu \mathrm{m})$. Increment intervals tested included the 1st and 2nd months, which correspond, respectively, to the pelagic larval stage and early juvenile stage adjacent to the seamounts, and Months 3 to 8 (young-of-the-year juveniles in subarctic waters). Other increment intervals analyzed included the 1st and 2nd pelagic year and the total (1.8 yr) pelagic interval examined. Subsampling of the 5-increment-width data over the latter 4 age intervals (every 2nd observation for Months 3 to 8 and 2nd pelagic year, every 3rd observation for the first pelagic year, and every 5th observation for the entire $1.8 \mathrm{yr}$ ) was required to ensure sample size exceeded measurements per individual and thus maintained MANOVAR test power (Potvin et al. 1990, Chambers \& Miller 1995). MANOVAR tests of these 6 age intervals examined the hypothesis that the mean increment-width profiles of recruits are the same among years of varied recruitment strength.

Statistical tests were performed using SAS/STAT Version 6.03 (SAS Institute 1988); statistical results with $\mathrm{p}<0.05$ were considered significant.

\section{RESULTS}

\section{Processed sagittal sections}

Transverse sagittal sections deemed satisfactory (increment sequence discernable from core to settlement mark) were produced for 96 SE Hancock Seamount recruits of Pseudopentaceros wheeleri (32 sections from each of the 3 recruit-years examined). Satisfactory sections were also produced for 77 pelagic-stage individuals, 14 Koko Seamount recruits, and 17 newly arrived recruits collected at SE Hancock in 1983 .

\section{Periodicity of increment deposition during pelagic phase}

Pelagic-stage individuals consisted of different age groups $(0+, 1+$, and $2+$ yr-olds $)$ and were analyzed separately (Table 1). A second sample of Age 1+ yr individuals (174 to $222 \mathrm{~mm}$ standard length, SL), collected together at the same time and site, were also analyzed separately. Only the Age 2+ yr (adult-size pelagics) group had backcalculated birthdate distributions not significantly different from that expected by chance
( $p=0.68)$. Pelagic individuals in each of the $<2$ yr-old age groups had $100 \%(p=0.0001)$ agreement of backcalculated birthdates to within the November to March spawning period.

\section{Settlement mark}

The presence of a settlement mark was indicated by the appearance of any one or combination of the following characters near the outer edge of transversely sectioned sagittae: (1) an abrupt decrease in increment-width, (2) a change to an eroded, less distinct appearance of the increments, and (3) the presence of 2 or more prominent and closely spaced 'check marks' (Fig. 2). No settlement mark was present in otolith sections of the 13 adult-size pelagics examined with light microscopy and the 3 also examined under SEM (Fig. 3). Except for 1 recruit without a settlement mark, virtually all (16 of 17) of the June 1983 sample of new recruits possessed a settlement mark close to the outer otolith edge (within 30 to $70 \mu \mathrm{m}$ ). This pattern of presence and absence of settlement marks among new recruits and adult-size pelagics, respectively, was highly significant $\left(\chi^{2}=28.2\right.$, df $\left.=1, p<0.001\right)$.

\section{Pelagic duration and recruit size}

Settlement marks were present in all transversely sectioned sagittae from the 3 recruit years examined. Pelagic duration ranged from 726 to 999 presumed days, and differed significantly between recruit years. The replicability of these increment counts was considered acceptable $(\mathrm{CV}=0.001$ to 0.048 , median $=$ 0.013). Mean pelagic duration of 1989 recruits was significantly greater (ANOVA, p < 0.01) than 1980 and 1986 recruits. Mean body length (FL) associated with the 1989 pelagic duration sample was also significantly larger (ANOVA, p < 0.01) than the 1980 and 1986 recruit samples (Table 2). Although ANOVA

Table 1. Pseudopentaceros wheeleri. Summary results of concordance of backcalulated birthdates (median and range), with November to March spawning period, among samples of several pelagic-stage age groups. SL: standard length

\begin{tabular}{|c|c|c|c|c|}
\hline $\begin{array}{l}\text { Age } \\
\text { group } \\
\text { (yr) }\end{array}$ & $\begin{array}{l}\text { Length } \\
\text { range } \\
\text { (mm SL) }\end{array}$ & $\begin{array}{l}\text { Sample } \\
\text { size }\end{array}$ & $\begin{array}{c}\text { Median } \\
\text { birthdate }\end{array}$ & $\begin{array}{c}\text { Range of } \\
\text { birthdates }\end{array}$ \\
\hline $0+$ & $72-124$ & 13 & Dec 29 & Dec 18-Jan 15 \\
\hline $1+$ & $182-219$ & 15 & Jan 12 & Dec 13-Feb 19 \\
\hline $1+$ & $174-222$ & 36 & Jan 18 & Nov 26-Mar 06 \\
\hline $2+$ & $233-279$ & 13 & Apr 17 & Jan 23-May 17 \\
\hline
\end{tabular}



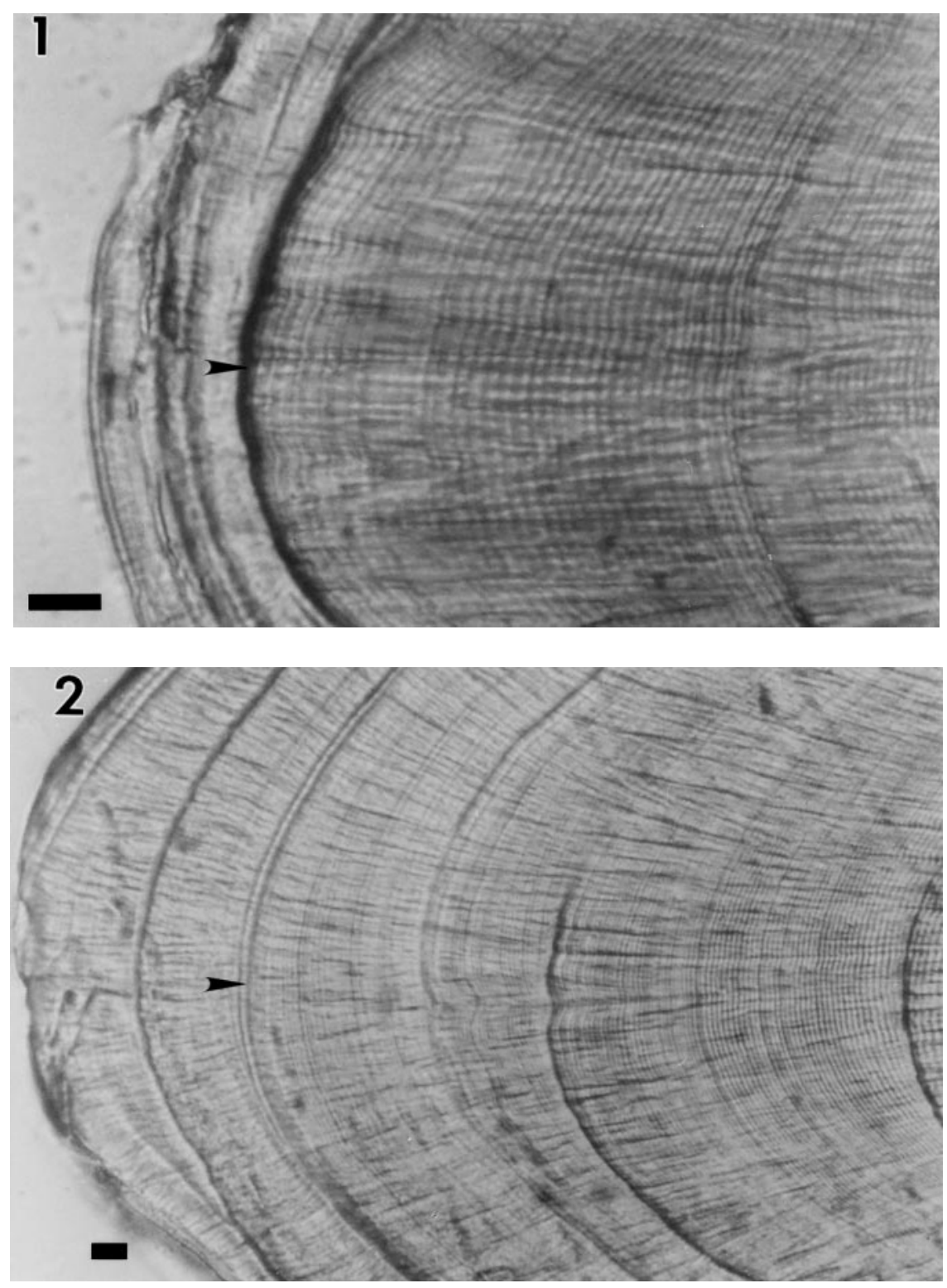

Fig. 2. Pseudopentaceros wheeleri. Light micrographs depicting variable appearance of post-settlement increments from abrupt (1) to more gradual (2) degradation in subsequent increment clarity. Arrowheads indicate settlement transition mark associated with seamount recruitment. Scale bars $=10 \mu \mathrm{m}$

assumes equal variance within categories, a nonparametric (Kruskal-Wallis) test of this data confirmed the ANOVA results.

The relative variation $\left(\mathrm{CV}^{\prime}\right)$ in pelagic duration for the 1980, 1986, and 1989 recruit years was 0.069, 0.058 , and 0.036 , respectively. However, the variation in body length for the corresponding recruit years was less than half, except in $1989\left(\mathrm{CV}^{\prime}=0.033,0.027\right.$, and 0.032 for the 1980, 1986, and 1989 recruit years, respectively). Body length (FL) was significantly less variable than pelagic duration in the $1980(t=3.69, \mathrm{p}<$
$0.001)$ and $1986(t=3.81, \mathrm{p}<0.001)$ recruit-year samples, but not in $1989(t=0.72, \mathrm{p}>0.2)$ (Fig. 4). In each of the $3(n=32)$ recruit-year samples, no correlation $(p>0.2)$ was found between pelagic duration and body length. When the data was pooled across the 3 recruit years, pelagic duration and body length were positively correlated $(p<0.01)$. A crude measure of average daily growth rate based on these 2 characteristics (mean body length, mean pelagic duration) is similar $\left(0.36 \mathrm{~mm} \mathrm{~d}^{-1}\right)$ in each recruit year. Mean body length of female SE Hancock recruits (fatness index, FI $\geq 0.26$ ) 


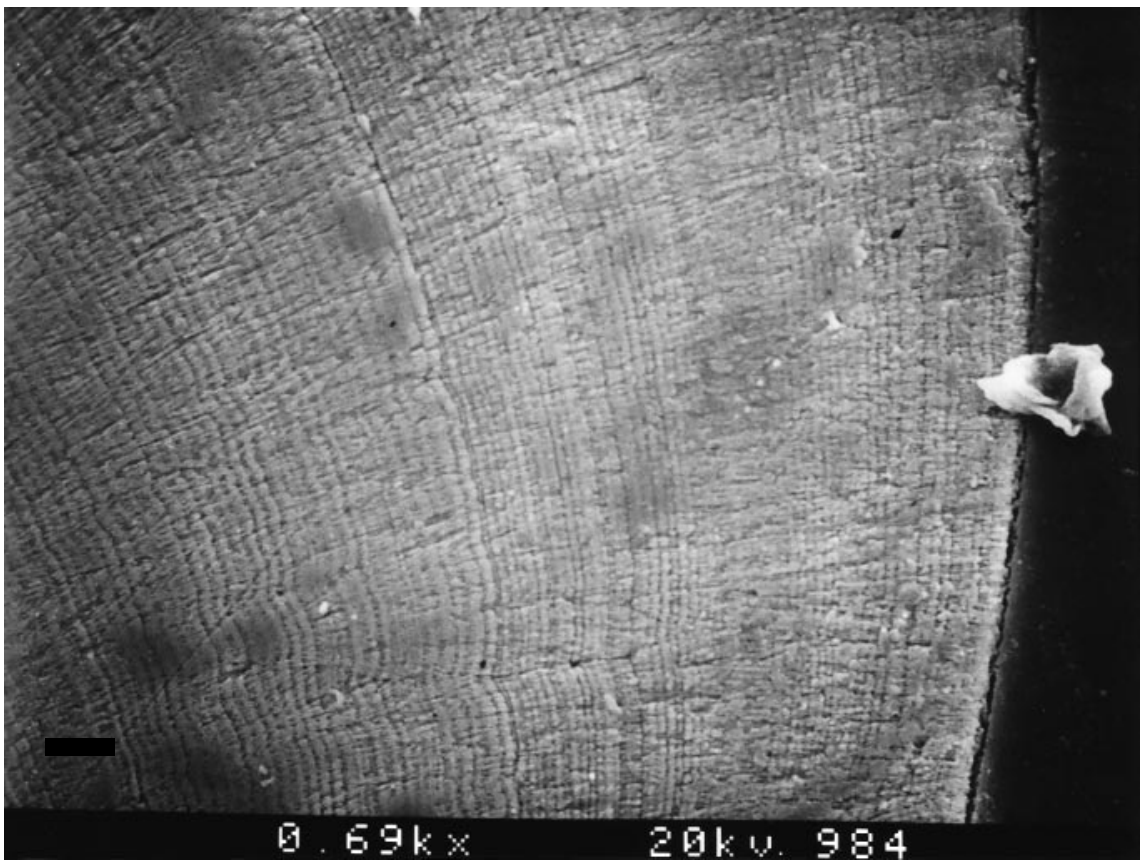

Fig. 3. Pseudopentaceros wheeleri. Scanning electron micrograph along outer edge of transversely sectioned sagitta from Age 2+ adult-size pelagic individual. Distinct increments are present out to very edge of this section. Scale bar $=10 \mu \mathrm{m}$

derived from the more extensive fishery-sampling database indicates that 1989 female recruits were significantly larger $(\mathrm{p}<0.001)$ than 1980 and 1986 female recruits, while the latter 2 recruit years also differed significantly ( $<<0.001$; Table 2 ). Additional female recruit-size data available from 10 other recruit years spanning weak (2 to $16 \mathrm{mt}, 1978,1981,1984,1985$, 1987, 1988, 1990, 1993), moderate (105 mt, 1992), and strong (1138 mt, 1973) recruitment indicated a significant inverse correlation between mean body length of female recruits and recruitment-biomass (Fig. 5). The greater $95 \%$ confidence interval associated with mean body length in the weaker recruit years is indicative of smaller ( $\mathrm{n}=50$ to 100$)$ available sample sizes.

\section{Increment-width profiles}

The mean 5-increment width profiles in each of the 3 recruit years along with those examined from Koko Seamount recruits and adult-size pelagics all displayed a generally similar dampened sine-wave shape

Table 2. Pseudopentaceros wheeleri. Summary results of recruit characteristics (pelagic duration and associated recruit fork length, FL, female recruit FL derived independently from cruise data, and cumulative increment width over first 365 and 660 series of increments out from the core) displayed by recruit-year and associated recruitment strength. For each character, mean and SD are displayed above sample size (n)

\begin{tabular}{|c|c|c|c|c|c|}
\hline \multirow{2}{*}{$\begin{array}{l}\text { Recruit- } \\
\text { year }\end{array}$} & \multirow{2}{*}{$\begin{array}{l}\text { Estimated } \\
\text { recruitment } \\
\text { biomass (t) }\end{array}$} & \multirow{2}{*}{$\begin{array}{l}\text { Pelagic duration (d) } \\
\text { Recruit FL (mm) }\end{array}$} & \multirow{2}{*}{$\begin{array}{l}\text { Female recruit } \\
\text { FL }(\mathrm{mm})\end{array}$} & \multicolumn{2}{|c|}{ Cumulative increment-width $(\mu \mathrm{m})$} \\
\hline & & & & 1st 365 increments & 1st 660 increments \\
\hline 1980 & 509 & $\begin{array}{c}848.1+57.7 \\
305.0+10.0 \\
n=32\end{array}$ & $\begin{array}{c}307.0+10.9 \\
\mathrm{n}=1268\end{array}$ & $\begin{array}{c}1429.1+99.0 \\
\mathrm{n}=22\end{array}$ & $\begin{array}{c}2004.0+148.9 \\
\mathrm{n}=22\end{array}$ \\
\hline 1986 & 58 & $\begin{array}{c}864.2+49.7 \\
308.2+8.2 \\
n=32\end{array}$ & $\begin{array}{c}312.3+10.1 \\
\mathrm{n}=1009\end{array}$ & $\begin{array}{c}1453.1+100.9 \\
\mathrm{n}=22\end{array}$ & $\begin{array}{c}2055.9+155.1 \\
n=22\end{array}$ \\
\hline 1989 & 1 & $\begin{array}{c}890.5+31.7 \\
319.7+10.0 \\
n=32\end{array}$ & $\begin{array}{c}323.3+10.9 \\
\mathrm{n}=76\end{array}$ & $\begin{array}{c}1336.0+99.5 \\
\mathrm{n}=22\end{array}$ & $\begin{array}{c}1970.5+146.5 \\
\mathrm{n}=22\end{array}$ \\
\hline
\end{tabular}



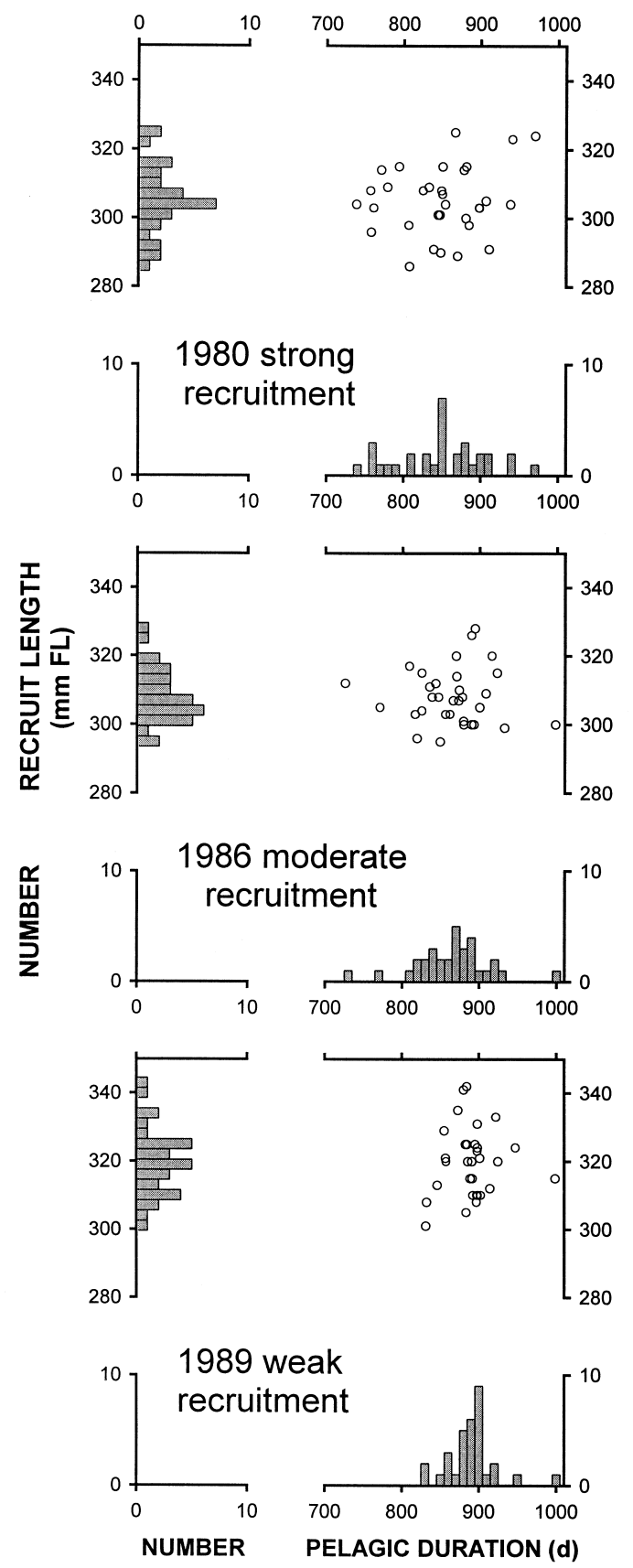

Fig. 4. Pseudopentaceros wheeleri. Combination scatter and histogram display of relationship between pelagic duration and body length (as fork length, FL) of recruits sampled from strong (1980), moderate (1986), and weak (1989) recruitment

years at SE Hancock Seamount $(n=32$ in each year)

of an approximately 1 yr cycle with significantly reduced amplitude in the 2nd year (Figs. 6 \& 7). Transitions in the width pattern (inflection points) along the sequential increment series of each of these mean increment profiles coincide at about the same ages. These inflection points primarily occur within the first

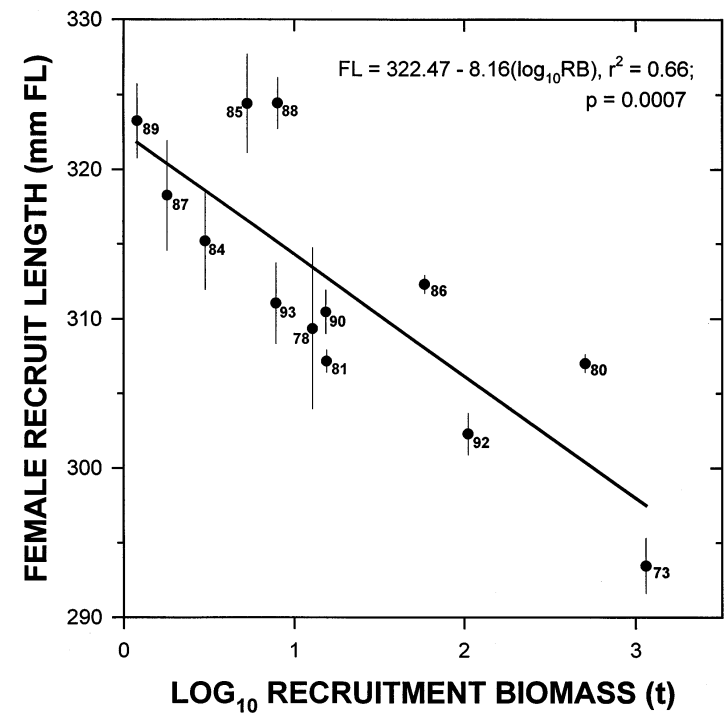

Fig. 5. Pseudopentaceros wheeleri. Relationship between $\log _{10}$ recruit-year biomass and mean FL (including $95 \%$ confidence limits) of female recruits based on both research cruises $(3 \mathrm{yr})$ and foreign-vessel sampling (10 additional years). Fitted regression indicates significant negative relationship between recruit size and recruitment strength

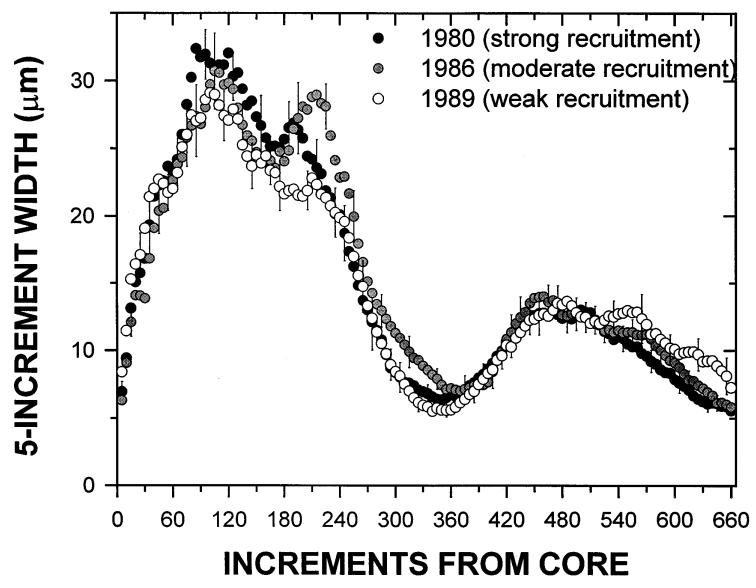

Fig. 6. Pseudopentaceros wheeleri. Mean 5-increment width profiles derived from SE Hancock recruits sampled from the strong, moderate, and weak recruit-years of 1980, 1986, and 1989, respectively ( $\mathrm{n}=22$ for each recruit year). For clarity, $95 \%$ confidence limits are only presented for every 6th 5 -increment mean width

pelagic year at Ages $\sim 3, \sim 6, \sim 7$, and $\sim 12$ mo. The MANOVAR tests of the 5-increment width sequences yielded significant differences in Age $\times$ Recruit-year effects at age intervals spanning the 2nd mo $(p<0.05)$, the 3rd to 8th mo $(p<0.01)$, the 1st year ( $p<0.001)$, the first 10 mo of the 2 nd year $(p<0.01)$, and the first $1.8 \mathrm{yr}$ of the pelagic phase examined $(p<0.001)$. Only within the $1 \mathrm{st}$ month of the pelagic phase were no significant 


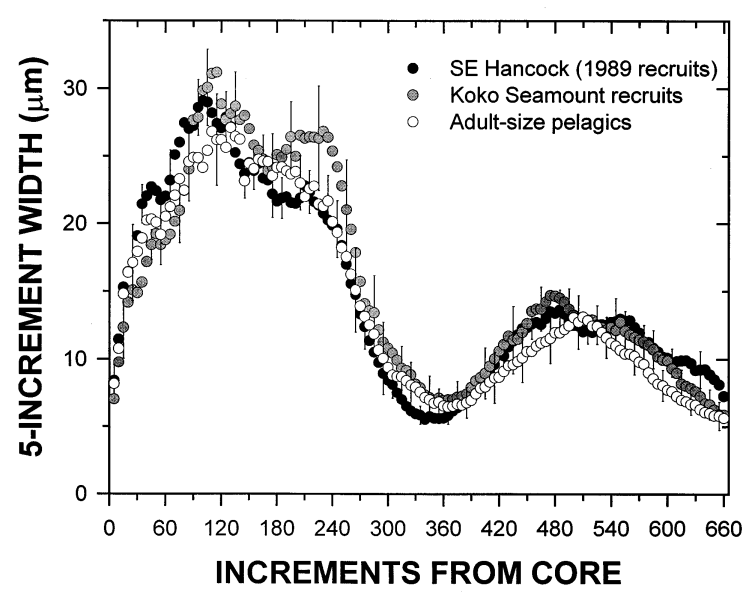

Fig. 7. Pseudopentaceros wheeleri. Comparison of mean 5increment-width profiles derived from Koko Seamount recruits $(n=14)$, adult-size pelagic individuals $(n=13)$ and, for reference, weak 1989 recruit year at SE Hancock $(n=22)$. For clarity, 95\% confidence limits are only presented for every 6 th 5 -increment mean width

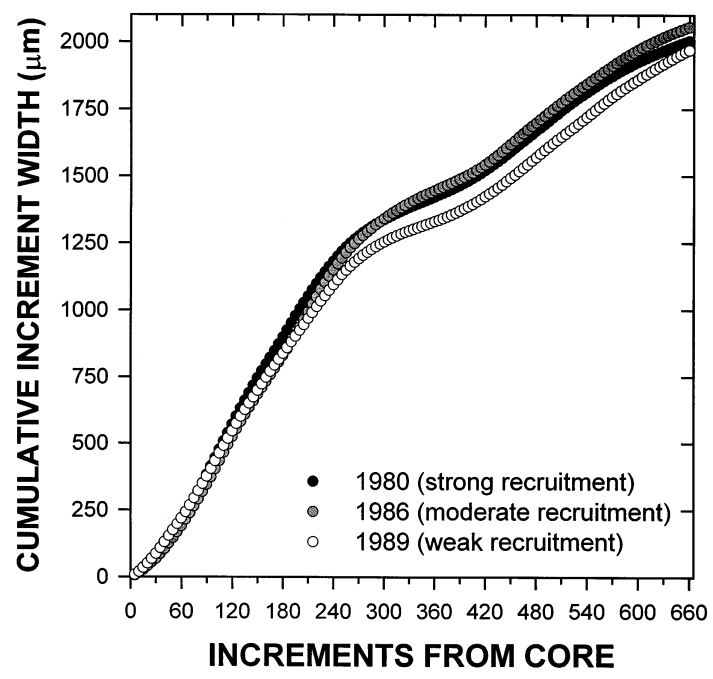

Fig. 8. Pseudopentaceros wheeleri. Mean cumulative 5-increment-width profiles derived from SE Hancock recruits sampled from strong, moderate, and weak recruit years of 1980,

1986, and 1989, respectively ( $\mathrm{n}=22$ for each recruit year)

recruit-year differences revealed (MANOVAR, $\mathrm{p}=$ 0.36 ). These same results were produced even when all the increment-width data in each age interval tested (subsampled in an effort to conserve test power) was included in the MANOVAR. Otolith section-angle and its interaction had no significant effect (MANOVAR, $0.09>p>0.95$ ) in any of the increment-width age-intervals analyzed.

Mean cumulative 5-increment-width by the end of the 1 st year was significantly smaller $(p<0.001)$ for the weak 1989 recruit year (Table 2, Fig. 8). In the 2nd pelagic year, however, the 1989 recruits produced wider increment-widths; enough so that no significant recruit-year differences $(p=0.18)$ were evident by the end of the first $1.8 \mathrm{yr}$.

\section{DISCUSSION}

\section{Characteristics of recruits common across recruit years}

The lengthy $(2-2+y r)$ pelagic stage and large nonreproductive adult size ( 27 to $33 \mathrm{~cm}$ FL) attained prior to recruitment are common characteristics among armorhead Pseudopentaceros wheeleri recruits; this combination of life-history traits is apparently rare among exclusively marine teleosts. Less relative variation in body length than pelagic duration was also common in each of the 3 recruit years.

The single 2-2+ yr age-class determined for both adult-size pelagics and recruits (pelagic duration) are contrary to a published report by Uchiyama \& Sampaga (1989) of 1 and 2 yr-old age-classes (primarily 1 yr-olds) in each of these life stages. The latter findings appear to have inadvertently resulted from the greater thickness of their prepared sagittae; this limited light microscopy examination to lower $(300 \times)$ magnification due to depth-of-field constraints.

The similar appearance of the temporal pattern of increment-width inflection points superimposed on the overall dampened sine-wave shape of the $1.8 \mathrm{yr}$ increment-width profile, exhibited among recruits in all 3 years (including recruits from a distant seamount and adult-size pelagic), suggests that these are common characteristics among individuals surviving to Age 2 yr. Furthermore, the similarity in increment-width profiles between SE Hancock Seamount (particularly the 1986 recruit-year) and Koko Seamount recruits lends support to the notion that these profile shapes are not seamount-specific within the SE-NHR seamounts.

\section{Characteristics of recruits relative to recruitment strength}

Beyond those traits that seem to generally characterize recruits, several significant character differences were evident. The weak 1989 recruit-year appears most different among the 3 recruit years in the combination of lower variability but longer mean pelagic duration and also longer body length. The overall inverse size-recruitment-strength relationship detected in this study has been similarly noted for Pacific 
pink and chum salmon (Ishida et al. 1993, Thomas \& Mathisen 1993) as well as for Pacific sockeye salmon (Pyper \& Peterman 1999). Borets (1977) proposed that the smaller body size of armorhead in a high-abundance year was produced by density-dependent constraints on pre-recruit growth. However, as with Pacific salmonids, interpretation of this relationship in regards to armorhead remains uncertain, and may represent the effects of both density-dependent and density-independent factors.

As with the other biological characters examined, the weak 1989 recruit-year displayed the most noticeable differences in increment-width pattern. The 1989 recruit year exhibited the smallest increment-widths at each of the 4 inflection points within the first year interval. Furthermore, virtually no inflection was present at Age $\sim 6$ mo and only weakly expressed at Age $\sim 7$ mo. This same inflection pattern is displayed in the mean increment-width profiles of adult-size pelagics. In ascending order of recruit-year strength, increasingly larger increment-widths occur at the first 2 inflection points at Ages $\sim 3$ mo and $\sim 6$ mo (including the interval between them). This relationship breaks down at Age $\sim 7$ mo and Age $\sim 12$ mo inflection points, where the pattern reverses between the strong (1980) and moderate (1986) recruit-years. Campana (1996) also found increment-width profiles which did not always differ appreciably between cohort-abundance levels of young Atlantic cod; in this case between the strongest and one of the weaker year-classes examined. However, Campana did find that both otolith (i.e. cumulative increment-width) and fish sizes at the pelagic juvenile stage (Age $90 \mathrm{~d}$ ) were significantly correlated with cohort abundance. Butler (1989) also reported greater increment-widths and somatic growth rates during the juvenile phase of northern anchovy in a strong versus weak recruitment-year comparison.

Our knowledge of the pelagic life-history, although incomplete, provides some context to interpret the temporal significance of these increment-width inflection points. Armorhead young are initially neustonic inhabitants in waters over and adjacent to the SE-NHR seamounts up to the first 3 mo of life (Sasaki 1974, Boehlert \& Sasaki 1988, Mundy \& Moser 1997). Subsequently, individuals apparently disperse, either actively or passively, and are later captured in surface waters of the central subarctic North Pacific by late spring-early summer (Boehlert \& Sasaki 1988). The first inflection in increment-width at Age $\sim 3$ mo may be temporally associated with the transition from seamount retention to dispersal toward subarctic waters. Recorded captures of the smallest individuals in subarctic waters are scarce, but indicate the occurrence of Age 3 to 5 mo-olds by late spring-early summer
(Boehlert \& Sasaki 1988). This suggests that by the second inflection point at Age $\sim 6$ mo, young-of-the-year individuals reside in subarctic surface waters. Aggregations of pelagic individuals found in sei whale stomachs and attracted to night-lights suggest that they school at or near the surface throughout the day (Chikuni 1970). Spring-summer captures of subarctic individuals are associated with sea-surface temperatures of 9 to $14^{\circ} \mathrm{C}$ (Boehlert \& Sasaki 1988). Among the young-of-the-year and 1-yr-old specimens examined for daily increment periodicity in this study, the inflection point at Age $\sim 7$ mo corresponds to early August (1990) and early September (1989), respectively. An explanation for the timing of the sharp inflection at Age $\sim 7 \mathrm{mo}$ and the rapid and sustained decline in increment-width thereafter remains problematic. The annual transition from summer to winter conditions in the subarctic North Pacific is typified by the rapid cooling of sea-surface temperatures (Favorite et al. 1976). This change begins in autumn, well after the Age $\sim 7$ mo inflection point is produced and well into the period of rapid increment-width decline. Whatever triggers this decline in increment-width, it is likely to occur in response to a wide-scale change within the surface waters of the central subarctic domain. No information exists on whether armorhead respond to this change by migrating south during fall/winter or remain in these cooler subarctic surface waters.

An unaccounted aspect of the pelagic life-history concerns the return of pelagic individuals to the SENHR seamounts. Boehlert \& Sasaki (1988) were unable to explain this return based on current flow, and proposed possible environmental cues that might guide individuals back. Despite these possible cues, the extent and/or direction of dispersal away from the seamounts may have an important effect on survival and subsequent recruitment levels (Boehlert \& Mundy 1993).

\section{Concluding comments}

Due to the lengthy duration of the pre-recruit phase, important early growth trends in armorhead may be completely obscured or erased from the subsequent 'recruit record' by intervening processes of selective mortality (Sogard 1997). Furthermore, the relative influence of endogenous and exogenous factors on the scaling of increment-width and the observed transitions (inflection points) in increment-width pattern remains unclear. Despite these limitations in the application of the increment-width record, the pattern of variation among recruit years, particularly around these inflection points within the first year of the increment record, suggests its potential use as an index of 
weak recruitment. Further study of this hypothesis on recruits from other weak recruit-years is feasible, although collections from additional moderate-tostrong recruit-years will require opportunistic sampling of these infrequent recruitment events. The 'characteristics of recruits' approach, particularly when pre-recruit surveys are not feasible, can provide a potentially valuable perspective in the continuing challenge to understand and predict recruitment variation.

Acknowledgements. I am grateful to B. Miller, J. Gunderson, J. Polovina, and E. DeMartini for guidance and advice during this study. I thank W. Barnett, A. Everson, T. Kazama, B. Kikkawa, K. Landgraf, M. Seki, N. Shippen, D. Somerton, J. Uchiyama, and the officers and crew of the NOAA RV 'Townsend Cromwell' for assistance in the collection of specimens and data at SE Hancock Seamount. I also acknowledge the assistance of the Pacific Biological Station, Nanaimo, BC, Canada and the officers and crew of the 'Oshoro Maru' and 'Tomi Maru No. 88' for their kindly donation of pelagic specimens. J. Uchiyama assisted in light microscope photography, and K. Landgraf and D. McGee assisted in SEM operations. I am particularly indebted to G. Boehlert for his support and encouragement. I thank G. Boehlert, C. Boggs, J. Butler, S. Campana, E. DeMartini, J. Polovina and the anonymous reviewers for their helpful comments on drafts of this manuscript.

\section{LITERATURE CITED}

Anderson JT (1988) A review of size dependent survival during pre-recruit stages of fishes in relation to recruitment. J NW Atl Fish Sci 8:55-66

Bakun A, Beyer J, Pauly D, Pope JG, Sharp GD (1982) Ocean sciences in relation to living resources. Can J Fish Aquat Sci 39:1059-1070

Bilim LA, Borets LA, Platoshina LK (1978) Characteristics of ovogensis and spawning of the boarfish in the region of the Hawaiian Islands. In: Fisheries oceanography, hydrobiology, biology of fishes and other denizens of the Pacific Ocean. Izv Tikhookean Nauchno-Issled Inst Ryb Khoz Okeanogr 102:51-57 (in Russisan) [Engl transl No. 106: Van Campen WG 1986; available from Southwest Fish Science Center, NOAA, Honolulu, Hawaii]

Boehlert GW, Mundy BC (1993) Ichthyoplankton assemblages at seamounts and oceanic islands. Bull Mar Sci 53: 336-361

Boehlert GW, Sasaki T (1988) Pelagic biogeography of the armorhead, Pseudopentaceros wheeleri, recruitment to isolated seamounts in the North Pacific Ocean. Fish Bull US 86:453-465

Borets LA (1976) The state of the boarfish, Pentaceros richardsoni (Smith) stock in the Hawaii submarine range areas. Izv Tikhookean Nauchno-Issled Inst Ryb Khoz Okeanogr 7:58-62 (in Russsian) [Engl transl No. 112: Van Campen WG 1987; available Southwest Fish Science Center, NOAA, Honolulu, Hawaii]

Borets LA (1977) Dynamics of size-age composition of the boarfish (Pentaceros richardsoni). Investigation of the biology of fishes and fishery oceanography. Izv Tikhookean Nauchno-Issled Inst Ryb Khoz Okeanogr 8: 65-69 (in Russian) [Engl transl No. 115: Van Campen WG
1987; available Southwest Fish Science Center, NOAA, Honolulu, Hawaii]

Butler JL (1989) Growth during the larval and juvenile stages of the northern anchovy, Engraulis mordax, in the California Current during 1980-84. Fish Bull US 87:645-652

Campana SE (1996) Year-class strength and growth rate in young Atlantic cod Gadus morhua. Mar Ecol Prog Ser 135: $21-26$

Chambers RC, Miller TJ (1995) Evaluating fish growth by means of otolith-increment analysis: special properties of individual level longitudinal data. In: Secor DH, Dean JM, Campana SE (eds) Recent developments in fish otolith research. Belle W Baruch Library in Marine Science, University of South Carolina Press, Columbia, p 155-175

Chikuni S (1970) On gregarious fish, Pseudopentceros richardsoni (Histiophoridae). Enyo (Far Seas) Fisheries Research Laboratory News 3:1-4 [Engl transl, The 'phantom fish,' 'kusakari tsubodai' — an outline: Shohara $\mathrm{JH}_{\text {; }}$ available National Marine Fisheries Service, NOAA, Terminal Island, California, USA

Favorite F, Dodimead AJ, Nasu K (1976) Oceanography of the subarctic Pacific region, 1960-1971. Bull Int N Pac Fish Commn 33:1-187

Frank KT (1991) Predicting recruitment variation from year class specific vertebral counts: an analysis of the potential and a plan for verification. Can J Fish Aquat Sci 48: 1350-1357

Frank KT, Leggett WC (1994) Fisheries ecology in the context of ecological and evolutionary theory. Annu Rev Ecol Syst 25:401-422

Fritz ES, Crowder LB, Francis RC (1990) The National Oceanic and Atmospheric Administration plan for recruitment fisheries oceanography research. Fisheries 15:25-31

Haldane JBS (1955) The measurement of variation. Evolution 9:484

Humphreys RL Jr, Winans GA, Tagami DT (1989) Synonymy and life history of the North Pacific pelagic armorhead, Pseudopentaceros wheeleri Hardy (Pisces: Pentacerotidae). Copeia 1:142-153

Humphreys RL Jr, Crossler MA, Rowland CM (1993) Use of a monogenean gill parasite and feasibility of condition indices for identifying new recruits to a seamount population of armorhead Pseudopentaceros wheeleri (Pentacerotidae). Fish Bull US 91:455-463

Ishida $\mathrm{Y}$, Ito $\mathrm{S}$, Kaeriyama $\mathrm{M}$, McKinnell $\mathrm{S}$, Nagasawa $\mathrm{K}$ (1993) Recent changes in age and size of chum salmon (Oncorhynchus keta) in the North Pacific Ocean and possible causes. Can J Fish Aquat Sci 50:290-295

Japan Fisheries Agency (1974) Survey of the North Pacific seamounts [Kita Taiheiyo kaizan chosa]. Report of Kaiyo Maru survey cruises, 1972 season. Japan Fisheries Agency [Transl from Japanese by Otsu $\mathrm{T}$ 1981: Transl No. 54: available Southwest Fish Science Center, NOAA, Honolulu, Hawaii]

Miller TJ (1997) The use of field studies to investigate selective processes in fish early life history. In: Chambers RC, Trippel EA (eds) Early life history and recruitment in fish populations. Chapman \& Hall, London, p 197-223

Mundy BC, Moser HG (1997) Development of early stages of pelagic armorhead Pseudopentaceros wheeleri with notes on juvenile Ps. richardsoni and larval Histiopterus typus (Pisces, Percoidei, Pentacerotidae). Bull Mar Sci 61: 241-269

Peterman RM, Bradford MJ, Lo NCH, Methot RD (1988) Contribution of early life stages to interannual variability in recruitment of northern anchovy (Engraulis mordax). Can J Fish Aquat Sci 45:8-16 
Potvin C, Lechowicz MJ, Tardif S (1990) The statistical analysis of ecophysiological response curves obtained from experiments involving repeated measures. Ecology 71: $1389-1400$

Pyper BJ, Peterman RM (1999) Relationship among adult body length, abundance, and ocean temperature for British Columbia and Alaska sockeye salmon (Oncorhynchus nerka), 1967-1997. Can J Fish Aquat Sci 56: 1716-1720

Rothschild BJ (1986) Dynamics of marine fish populations. Harvard, Cambridge

Sasaki T (1974) The pelagic armorhead, Pentaceros richardsoni Smith, in the North Pacific [Kita Taiheiyo no kusakari tsubodai]. Bull Jap Soc Fish Oceanogr 24:156-165 [Transl from Japanese by Otsu T 1977: Transl No. 16: available Southwest Fish Science Center, NOAA, Honolulu, Hawaii]

Sasaki T (1986) Development and present status of Japanese trawl fisheries in the vicinity of seamounts. Nat Mar Fish Serv Tech Rep US Dep Comm 43:21-30

Sogard SM (1997) Size-selective mortality in the juvenile stage of teleost fishes: a review. Bull Mar Sci 60: 1129-1157

Sokal RR, Braumann CA (1980) Significance tests for coefficients of variation and variability profiles. Syst Zool 29: $50-66$

Somerton DA, Kikkawa BS (1992) Population dynamics of pelagic armorhead Pseudopentaceros wheeleri on Southeast Hancock Seamount. Fish Bull US 90:756-769

SAS Institute (1988) SAS/STAT user's guide. Release 6.03 edn. SAS Institute, Cary, NC, USA

Taggart CT, Frank KT (1990) Perspectives on larval fish ecol-

Editorial responsibility: Otto Kinne (Editor),

Oldendorf/Luhe, Germany ogy and recruitment processes: probing the scales of relationships. In: Sherman K, Alexander LM, Gold BD (eds) Large marine ecosystems: patterns, processes, and yields. American Association for the Advancement of Science, Washington, DC, p 151-164

Takahashi Y, Sasaki T (1977) Trawl fishery in the central North Pacific seamounts [Kita Taiheiyo chubu kaizan ni okeru tororu gyogyo]. Hokuyo soko-uo gyogyo-Shiryo: 3 [Northern waters groundfish fishery-Data: 3]. Division of Northern Waters Groundfish Resources, Far Seas Fisheries Research Laboratory. [Transl from Japanese by Otsu T 1977: Transl No. 22: available Southwest Fisheries Center, NMFS, NOAA, Honolulu, Hawaii]

Thomas GL, Mathisen OA (1993) Biological interactions of natural and enhanced stocks of salmon in Alaska. Fish Res 18:1-17

Tyler AV (1992) A context for recruitment correlations: why marine fisheries biologists should still look for them. Fish Oceanogr 1:97-107

Uchida RN, Tagami DT (1984) Groundfish fisheries and research in the vicinity of seamounts in the North Pacific Ocean. Mar Fish Rev 46:1-17

Uchiyama JH, Sampaga JD (1989) Age estimation and composition of pelagic armorhead Pseudopentaceros wheeleri from the Hancock Seamounts. Fish Bull US 88:217-222

Wetherall JA, Yong MYY (1986) Problems in assessing the pelagic armorhead stock on the central North Pacific seamounts. Nat Mar Fish Serv Tech Rep US Dep Comm 43:73-85

Zar JH (1984) Biostatistical analysis, 2nd edn. Prentice-Hall, Inc, Englewood Cliffs, NJ

Submitted: May 5, 1997; Accepted: January 7, 2000

Proofs received from author(s): September 6, 2000 